1 Universidade Federal do Acre (Ufac) - Rio Branco (AC), Brasil.

luci_teston@hotmail.com

2 Universidade de São Paulo (USP) - São Paulo (SP), Brasil.

3 Universidade Federal de São Paulo (Unifesp) - São Paulo (SP), Brasil.

\section{Desafios políticos e operacionais na percepção de gestores sobre a regionalização em saúde no Acre}

\author{
Political and operational challenges in the perception of managers on \\ health regionalization in Acre
}

Luci Maria Teston', Áquilas Mendes ${ }^{\mathbf{2}}$, Leonardo Carnut ${ }^{\mathbf{3}}$, Marília Cristina Prado Louvison²

DOI: 10.1590/0103-1104201912102

RESUMO Uma das estratégias para a efetivação da implantação do Sistema Único de Saúde é a regionalização da saúde. É um princípio orientador do processo de negociações e pactuações entre entes públicos em regiões de saúde por meio de uma gestão compartilhada. Este artigo analisa as percepções dos gestores municipais sobre os desafios políticos e operacionais da implantação da regionalização em saúde no estado do Acre. Para isso, foram realizados três grupos focais com os secretários municipais de saúde, um em cada região de saúde do estado. Os resultados apontaram que os secretários municipais consideram a Comissão Intergestores Regional um espaço cartorial, ao mesmo tempo em que evidenciam a falta de capacidade técnica, financeira e de estrutura física dos municípios para cumprirem as metas do Contrato Organizativo da Ação Pública da Saúde. Também ressaltam as barreiras geográficas e $\mathrm{o}$ atendimento a estrangeiros em municípios situados em regiões de fronteira. Há a necessidade do empoderamento das decisões nas regiões de saúde, a partir da construção de propostas relacionadas à garantia do financiamento e da gestão de recursos no âmbito regional, às barreiras geográficas existentes nos municípios e à revisão do critério demográfico para a transferência de recursos em regiões de fronteira.

PALAVRAS-CHAVE Sistema Único de Saúde. Políticas públicas de saúde. Regionalização. Geografia.

ABSTRACT One of the strategies for the implementation of the Unified Health System is the regionalization of health. It is a guiding principle of the process of negotiations and agreements between public entities in health regions through shared management. This article analyzes the perceptions of the municipal managers on the political and operational challenges of the implementation of regionalization in health in the state of Acre. For this, three focus groups were carried out with the municipal health secretaries, one in each health region of the state. The results showed that the municipal secretaries consider the Regional Interagency Commission a notarial space, at the same time as evidencing the lack of technical, financial and physical capacity of the municipalities to fulfill the goals of the Organizational Contract of Public Health Action. They also highlight geographical barriers and assistance to foreigners in municipalities located in border regions. There is a need for empowerment of decisions in health regions, from the construction of proposals related to ensuring funding and resource management at the regional level, to existing geographical barriers in municipalities and to revising the demographic criterion for the transfer of resources in regions border.

KEYWORDS Unified Health System. Public health policy. Regional health planning. Geography. 


\section{Introdução}

Várias estratégias têm sido criadas no processo de implantação do Sistema Único de Saúde (SUS) visando à sua efetivação. Entre elas, estão a organização e a integração das ações e dos serviços em 'regiões de saúde', com a finalidade de garantir a integralidade da assistência aos usuários do sistema em uma escala geograficamente razoável.

Preconizado pelo Decreto $\mathrm{n}^{0} 7.508 / 2011$, o Contrato Organizativo da Ação Pública da Saúde (Coap) veio regulamentar a Lei Orgânica da Saúde (Lei no 8.080/1990), recepcionada pela Constituição Federal do Brasil de 1988, a qual apresenta a regionalização e a hierarquização das ações e dos serviços de saúde como princípios norteadores dos processos de organização político-territorial do SUS'.

As regiões, em tese, constituem-se como base territorial com autossuficiência, mesmo representando espaços geográficos ligados à condução político-administrativa do sistema de saúde no território. Diante desta característica, o processo de regionalização torna-se complexo em virtude da necessidade de convergirem politicamente questões pouco compatíveis, como, por exemplo, a institucionalização de uma rede homogênea de serviços e ações frente à heterogeneidade territorial em termos de desigualdades ${ }^{2}$.

Cada região de saúde tem uma Comissão Intergestores Regional (CIR), espaço colegiado de articulação intergovernamental com atribuições relacionadas à negociação e à pactuação das ações e dos serviços de saúde. Submetida ao poder fiscalizador e, supostamente, deliberativo dos conselhos de saúde, as CIRs procuram realizar debates que promovam acordos e parcerias entre as esferas de governo no processo de formulação e implementação da política de saúde na região ${ }^{2,3}$.

Historicamente, a CIR começou a ser implantada em 2006, e vem obedecendo a um ritmo próprio em cada estado da federação ${ }^{3}$. No caso do Acre, a Resolução da Comissão Intergestora Bipartite (CIB) no 36/2012 pactuou o reconhecimento de três CIRs, uma em cada região de saúde existente ${ }^{\mathbf{4}}$. A primeira região de saúde compreende o 'Baixo Acre e Purus', e é composta por 11 municípios: Rio Branco (sede), Acrelândia, Bujari, Capixaba, Jordão, Manoel Urbano, Plácido de Castro, Porto Acre, Santa Rosa do Purus, Sena Madureira e Senador Guiomard. A capital, Rio Branco, com $46 \%$ da população do estado, concentra a maior parte da infraestrutura administrativa estadual e dos serviços de saúde oferecidos ${ }^{5}$.

A segunda região de saúde, denominada 'Alto Acre', abrange os municípios de Brasileia (sede), Xapuri, Assis Brasil e Epitaciolândia. Brasileia e Epitaciolândia fazem fronteira com a Bolívia, e Assis Brasil está localizado na tríplice fronteira entre Brasil, Peru e Bolívia. Por estarem geograficamente localizados em região de fronteira, populações de outros países acessam o sistema de saúde destes municípios.

A região do 'Juruá, Tarauacá/Envira' é composta por sete municípios: Cruzeiro do Sul (sede), Mâncio Lima, Rodrigues Alves, Marechal Thaumaturgo, Porto Walter, Tarauacá e Feijó. Situados na parte ocidental do estado, Santa Rosa do Purus, Jordão, Marechal Thaumaturgo e Porto Walter possuem baixas densidades demográficas, e seu acesso dá-se primordialmente por via fluvial ou, quando aéreo, em aeronaves de pequeno porte. Estão situados em uma região onde predominam grandes rios e vasta extensão de florestas.

As regiões de saúde foram criadas seis anos após a elaboração do Plano Diretor de Regionalização (PDR), em 2003. No PDR daquele ano, enfatizou-se que a implantação da regionalização exigiria um enorme esforço de pactuação dos diversos níveis gestores do sistema, no sentido de serem estabelecidas estratégias que atendessem às especificidades regionais e locais para a solução dos principais problemas de saúde e ajudassem a superar os entraves para a organização da assistência ${ }^{6}$.

No documento, enfatizou-se que o processo de regionalização do SUS no estado estava ocorrendo de forma mais lenta, se comparado ao restante do País, devido a características 
peculiares. Entre elas, chama atenção o fato de grande parte dos municípios não possuírem capacidade técnica, administrativa e operacional para assumirem responsabilidades mínimas na atenção básica, além do montante insuficiente de recursos transferidos pelo Ministério da Saúde (MS) para o custeio da atenção básica e, especialmente, as barreiras geográficas de acesso da população aos serviços de saúdé . $^{2}$

A distribuição não uniforme de modalidades e tipos de serviços relacionados ao sistema de saúde pública também é observada no plano nacional. As diferenças entre os entes federados são significativas e muitos municípios de pequeno porte populacional não conseguem abrigar todos os níveis de atenção dentro de seus limites geográficos. Geralmente, em tais municípios existem apenas estabelecimentos de atenção básica, ficando a concentração de oferta de serviços especializados e de alta complexidade em poucos municípios ${ }^{2}$.

A população do Acre, em 2016, foi estimada em mais de 800 mil habitantes. Destes, 94\% utilizam os serviços de assistência direta do SUS cotidianamente ${ }^{7}$. Este predomínio do SUS no estado, a concentração dos serviços de saúde na capital, Rio Branco, as barreiras geográficas existentes e a localização de municípios em regiões de fronteira reforçam a necessidade de estudos que investiguem a dinâmica do processo de regionalização em saúde de um estado tão singular como este. Desta forma, o presente estudo tem por objetivo analisar as percepções dos gestores municipais sobre os desafios políticos e operacionais da implantação da regionalização em saúde no estado do Acre.

\section{Métodos}

Trata-se de um estudo de cunho qualitativo, alicerçado na técnica dos grupos focais, que possibilita, via interação dos participantes, a emergência de dados e percepções que talvez não estivessem acessíveis por meio da realização de entrevistas individuais ou da aplicação de questionários. Pode ser utilizada para gerar ou formular teorias, identificar conceitos, crenças, percepções, expectativas, motivações e necessidades de um grupo específico de interesse do pesquisador ${ }^{8}$.

No estado do Acre, há três regiões de saúde, e foram realizados três grupos focais, um em cada região. Foram sujeitos da pesquisa os secretários municipais de saúde. O primeiro grupo foi realizado em novembro de 2015, em Cruzeiro do Sul, na sede da regional do 'Juruá, Tarauacá/Envira', e contou com a presença de quatro secretários e dois representantes designados. Cruzeiro do Sul é o segundo município mais populoso do Acre, distando 635 $\mathrm{km}$ da capital, Rio Branco.

Na região de saúde do 'Baixo Acre e Purus', o grupo focal foi realizado na Secretaria Municipal de Saúde do município de Rio Branco, capital do estado, em janeiro de 2016, e contou com a presença de cinco secretários e um representante designado. Dois municípios que compõem esta região, Santa Rosa do Purus e Jordão, possuem as densidades demográficas mais baixas do estado e são acessíveis somente por via fluvial - navegação, considerada o caminho tradicional da Amazônia brasileira -, e aérea, em aeronaves de pequeno porte.

Na região do 'Alto Acre', o grupo focal foi realizado em fevereiro de 2016, na Secretaria Municipal de Saúde de Brasileia, e contou com a presença de três dos quatro secretários municipais de saúde daquela regional. O município é distante $235 \mathrm{~km}$ da capital, Rio Branco, e faz divisa com a Bolívia, com acesso terrestre, inclusive com transporte regular de ônibus.

Em relação às principais recomendações para essa técnica, a literatura indica uma variação entre 6 e 15 participantes por grupo focal, mas também aponta que o tamanho ideal corresponde àquele que permite a discussão adequada dos temas e a verdadeira participação dos sujeitos ${ }^{9}$. Dessa forma, houve uma particularidade em relação à região do 'Alto Acre', ao se optar por manter o grupo focal mesmo com um número de participantes abaixo do recomendado pela literatura, 
tendo em vista que apenas quatro municípios pertencem àquela regional.

Nos grupos focais, buscou-se favorecer a troca de informações, visto que havia pessoas do mesmo nível hierárquico (secretários municipais de saúde). Além disso, entendeu-se que havia grupos heterogêneos, na medida em que foram verificadas diferentes compreensões sobre o tema do estudo, bem como diferentes posições político-partidárias. Houve a presença de um moderador, responsável por conduzir a atividade enquanto propunha questões aos participantes e buscava manter o foco na discussão, e de um observador, que acompanhou a atividade e, após a realização do grupo, contribuiu para o relato dos acontecimentos.

Um roteiro orientou a dinâmica dos grupos focais, estruturado a partir de temas envolvendo a articulação regional, o processo de gestão no âmbito da CIR, os instrumentos de gestão e de atenção à saúde e os desafios para a região. Inicialmente, foram apresentados o objetivo do estudo e sua contribuição para o entendimento do processo de regionalização da saúde no Acre. Em seguida, foram informados aos sujeitos da pesquisa a gravação das falas e a garantia do sigilo. A participação na pesquisa pressupôs a sua compreensão e a livre escolha de dela fazer parte, o que foi comprovado pela assinatura do Termo de Consentimento Livre e Esclarecido (TCLE).

As reuniões foram gravadas e transcritas manualmente, na íntegra. Para a análise dos dados foi aplicada a técnica de análise de conteúdo proposta por Bardin ${ }^{10}$. Iniciou-se pelo que uma das autoras chamou de 'leitura flutuante', para, em seguida, identificarem-se as unidades temáticas presentes nas falas dos sujeitos da pesquisa e, posteriormente, proceder-se à construção de categorias e subcategorias de análise, cada vez mais específicas e precisas em relação ao objeto da pesquisa e em torno das quais foram organizados os discursos dos sujeitos, considerando a proximidade dos temas. Por fim, com a composição dessa estrutura, procedeu-se à análise das informações obtidas.

Para fins de análise, identificaram-se os Grupos Focais como GF1, GF2 e GF3, assegurando o anonimato dos gestores municipais. O estudo foi desenvolvido considerando as diretrizes e normas estabelecidas para pesquisas com seres humanos contidas na Resolução no 466/2012 do Conselho Nacional de Saúde. O projeto foi aprovado pelo Comitê de Ética em Pesquisa da Faculdade de Saúde Pública da Universidade de São Paulo (Parecer $\mathrm{n}^{\circ}$ 1.368.889).

\section{Resultados e discussão}

A partir da análise das falas, emergiram três categorias temáticas: a) Aplicabilidade do Coap e percepções sobre a CIR; b) Barreiras geográficas existentes nos municípios; e c) Percepções sobre o modelo de atenção básica. Destas categorias, emergiram algumas subcategorias (quadro 1). 
Quadro 1. Categorias e subcategorias emergentes sobre a unidade temática 'regionalização em saúde no Acre' nos grupos focais com gestores municipais. Acre, 2016

\begin{tabular}{|c|c|c|}
\hline $\begin{array}{l}\text { Unidade } \\
\text { Temática }\end{array}$ & Categoria & Subcategorias \\
\hline \multirow[t]{4}{*}{$\begin{array}{l}\text { REGIONALI- } \\
\text { ZAÇÃO EM } \\
\text { SAÚDE NO } \\
\text { ACRE }\end{array}$} & Percepções sobre a CIR & $\begin{array}{l}\text { - Espaço cartorial; } \\
\text { - Tomada de decisão individual; } \\
\text { - Pouca participação dos secretários nas reuniões; } \\
\text { - Falta empoderamento da região de saúde. }\end{array}$ \\
\hline & $\begin{array}{l}\text { Aplicabilidade do Coap no } \\
\text { âmbito regional }\end{array}$ & $\begin{array}{l}\text { - Redes de atenção à saúde desorganizadas; } \\
\text { - Municípios sem estrutura para cumprirem as metas; } \\
\text { - Processo vertical, sem consulta aos municípios; } \\
\text { - Falta de gerenciamento do Fundo Municipal de Saúde. }\end{array}$ \\
\hline & $\begin{array}{l}\text { Barreiras geográficas existen- } \\
\text { tes nos municípios }\end{array}$ & $\begin{array}{l}\text { - Mesmos critérios para regiões diferentes; } \\
\text { - Acesso às populações isoladas; } \\
\text { - Atendimento à população de outros países; } \\
\text { - Financiamento da saúde insuficiente. }\end{array}$ \\
\hline & $\begin{array}{l}\text { Percepções sobre o modelo } \\
\text { de atenção básica }\end{array}$ & $\begin{array}{l}\text { - Modelo ambulatorial; } \\
\text { - Municípios extrapolam suas competências; } \\
\text { - Fragmentação de programas, ações e serviços; } \\
\text { - Cobranças de outras esferas de gestão. }\end{array}$ \\
\hline
\end{tabular}

Fonte: Elaboração própria.

\section{Aplicabilidade do Coap e percepções sobre a CIR}

Para os gestores municipais de saúde, não há condições dos municípios pactuarem o Coap. Os depoimentos revelam as razões: a) necessidade de organização das redes de atenção à saúde nas regiões; b) falta de estrutura nos municípios para o cumprimento das metas estipuladas; c) processo vertical de implementação do Contrato, no qual os municípios serão mais punidos do que beneficiados.

As falas refletem as dificuldades: "Não podemos fazer o Coap agora porque nós não conseguimos nem organizar as redes" (GF1). Outro gestor enfatiza: "Muitas coisas foram empurradas 'goela abaixo' para o município, sem a gente ter participação na elaboração e condição de assumir tudo isso" (GF2).

Eu vou ter que assinar o Contrato dizendo que vou realizar aquilo, que vou chegar naquela meta. E se eu não chegar? Eu tenho quase certeza que algumas metas eu não consigo. Não tem condições, eu vou estar sendo responsabilizado, o município vai estar sendo responsabilizado por uma coisa que ele não tem condições de fazer. (GF1).

As dificuldades relatadas nos depoimentos revelam um horizonte distante e incerto em relação a esse espaço de negociação interfederativa regional. Neste sentido, Santos e Campos $^{11}$ alertam para a necessidade de o Coap não ser deturpado, no sentido de se transformar em um documento de adesão, que nasce pronto em apenas uma esfera de governo. Os autores destacam que o ordenamento político-jurídico brasileiro dificulta a construção da região. Além disto, evidenciam a necessidade de se buscarem soluções para a região de saúde, as quais envolvem aspectos administrativos e sanitários. Lembram, ainda, que o processo de municipalização rompeu com o centralismo na saúde, porém este foi um processo competitivo e pouco solidário.

Nesse sentido, observa-se que as secretarias municipais de saúde, apesar de estarem amparadas pelos instrumentos de planejamento, na maioria das vezes apresentam-se como simples 
'prestadoras de serviços', quase como 'agências' reguladas pelo executivo da mesma esfera, ou ainda por esferas supramunicipais ${ }^{12,13}$. O planejamento dos recursos é elaborado pelas prefeituras e, em alguns casos, a direção dos recursos não indica a necessidade da população. Isto pode ser exemplificado na fala de alguns dos gestores, quando afirmam que a grande maioria dos secretários de saúde do estado do Acre não gerencia o Fundo Municipal de Saúde (FMS). Esta falta de controle sobre o Fundo é percebida como fator negativo para o alcance dos resultados em saúde preconizados pelo município. "Você, que gerencia no município, já tem dificuldade. E quem não gerencia, que fica na mão do prefeito? É ele quem define o que vai fazer?" (GF2).

Para Mendes e Louvison ${ }^{\mathbf{1 4}}$, o Coap busca firmar um acordo de colaboração entre os entes federativos, com a finalidade de organizar e integrar as ações e serviços de saúde em uma rede regionalizada e hierarquizada, com definição de responsabilidades, indicadores e metas de saúde, critérios de avaliação de desempenho e recursos financeiros que serão disponibilizados. Para Tamaki et al..$^{15}$, o desafio do decreto é inovar nos processos e instrumentos de gestão, superar a fragmentação das políticas de saúde e garantir o acesso com qualidade, fortalecendo os vínculos interfederativos.

Compreensão semelhante é percebida em relação à CIR. Os participantes da pesquisa reconhecem o seu potencial enquanto instância que promove o fortalecimento da política de regionalização em saúde. Entretanto, percebem que este espaço tem se tornado cartorial, no sentido de ser formalmente criado e utilizado para referendar decisões já pactuadas. Os secretários não a consideram como uma instância de planejamento, pactuação e cogestão solidária entre os gestores municipais de saúde.

Quando diz que tem que ser aprovado pela CIR, senão não passa no estado, aí, a gente: 'Olha tem que aprovar isso aqui porque, se não aprovar, a gente não recebe tal recurso', 'Tem a reunião, a gente vai discutir o quê mesmo?'. A gente vai até reunir e tal, mas de CIR mesmo não tem o que decidir. (GF3).

As decisões mais importantes, segundo o relato dos participantes, não são tomadas em colegiado, o que contribui para fragilizar e desarticular o processo de pactuação na região. Ou seja, os secretários buscam articulações políticas e/ou técnicas no âmbito estadual e não na região de saúde da qual fazem parte. Este cenário tende a dificultar a descentralização política e a atuação do colegiado e, como resultado, tem-se uma CIR com fraca articulação técnica e política, e pouca representatividade regional. Neste cenário, predomina a atuação da secretaria estadual de saúde na condução do processo de regionalização.

De maneira geral, salientam Noronha et al. ${ }^{3}$, os gestores do SUS atuam nas esferas política e técnica. A política compreende o relacionamento dos gestores com outros atores sociais, no âmbito dos diferentes espaços de negociação e de decisões. Isto implica considerar que os gestores não exercem suas funções de forma isolada, havendo, portanto, negociações com diversos atores governamentais e não governamentais quanto aos objetivos e planos de ação e, deste modo, os processos de formulação e implementação das políticas de saúde assumem um aspecto compartilhado. Neste contexto, aos gestores cabe "assumirem a liderança da negociação política em defesa da implementação dos princípios e diretrizes do SUS"3(372).

A perspectiva técnica, por seu lado, não deixa de trazer elementos políticos, posto que a atuação do gestor do SUS consubstancia-se por meio do exercício das funções gestoras na saúde e, portanto, está permanentemente permeada por variáveis políticas ${ }^{3}$.

Como resultado dessa falta de tomada de decisão no âmbito do colegiado, há pouca participação dos secretários municipais nas reuniões da CIR. Muitas são canceladas por falta de quórum e, frequentemente, não há um calendário de reuniões ordinárias. Entre as justificativas para esse cenário foram apontados problemas de logística. 
Acontece que os municípios deixam de ir às reuniões. Para que vai se largar daqui numa estrada dessa, complicada? O município não pode mais pagar diárias, está tudo suspenso. (GF3).

Essa dificuldade é assinalada em outro depoimento:

Ontem, eu saí de lá e vim num transporte que acharia que poderia ser mais rápido. Gastei 12 horas e meia de viagem, e não tinha outro meio aéreo e fluvial. (GF1).

No entendimento de alguns secretários, esse ‘esvaziamento' da CIR enquanto espaço de cooperação e pactuação seria reflexo do pouco diálogo estabelecido com os municípios, quando da proposta de criação da Comissão. Ou seja, a CIR tem se tornado um espaço cartorial, em parte, como consequência de um processo de constituição entendido como vertical, sem o debate adequado com os municípios. "Na verdade, as CIRs, elas não disseram por que vieram, é vindo de cima pra baixo" (GF3).

Para a CIR cumprir sua missão de ser um espaço permanente de pactuação e cooperação dos gestores nas regiões de saúde, há a manifestação da necessidade do empoderamento das decisões, conforme se observa na fala a seguir:

Existem regiões que não estão fortalecidas, há o desenho, mas não há uma liberdade de trabalho. Você tem uma gerência regional, uma coordenação regional, mas eu acho que tinha que funcionar nas regiões os recursos, o empoderamento do gestor da região para tomar as decisões. (GF1).

Ao observarem a CIR no estado do Acre, Rodrigues et al. ${ }^{16}$ entenderam que a falta de reuniões ordinárias poderia sinalizar a fragilidade dos pactos cooperativos entre as regiões de saúde e o enfraquecimento das políticas de saúde concernentes à necessidade da população. As falas dos secretários municipais durante os grupos focais evidenciaram essa falta de participação, consequência de instâncias colegiadas regionais cartoriais, frágeis, desarticuladas e pouco empoderadas.

\section{Barreiras geográficas existentes nos municípios}

A regionalização é influenciada pelas relações estabelecidas entre diferentes atores sociais no espaço geográfico, envolvendo governos, organizações e cidadãos. Inclui o desenvolvimento de estratégias e instrumentos de planejamento, integração, gestão, regulação e financiamento de uma rede de ações e serviços, no território. Neste contexto, as múltiplas realidades territoriais existentes e a importância adquirida pelas instâncias estaduais e municipais na condução da política de saúde influenciam o processo de regionalização do SUS nos estados brasileiros ${ }^{2}$.

Embora haja uma tendência à redução das diferenças entre os municípios quanto à participação no total da produção de serviços básicos, estas permanecem grandes no que diz respeito ao acesso aos serviços. Para Lima et al. ${ }^{17}$, se há a pretensão de conferir maior efetividade às políticas de saúde, é necessário que, na formulação de propostas e na implementação de estratégias de regionalização, a diversidade de situações geográficas existentes no País seja considerada.

Em diagnóstico realizado pela Secretaria de Saúde do Estado do Acre (Sesacre) para a elaboração do PDR são apontadas barreiras geográficas de acesso da população aos serviços de saúde. Entre as dificuldades estariam a pouca quantidade de estradas (vias terrestres de acesso) aliada ao fato de alguns municípios fronteiriços também não serem acessíveis por via fluvial em determinado período do ano. Além disto, o documento destaca o grande número de referências feitas por transporte aéreo para a capital, o que representaria, para o estado, um elevado custo de Tratamento Fora do Domicílio (TFD) ${ }^{6}$.

Os depoimentos dos secretários municipais nas regiões de saúde confirmam as dificuldades enfrentadas quanto às barreiras geográficas existentes. Entre elas, emerge o problema 
do acesso às populações isoladas relatado pelas equipes de profissionais de saúde. Em geral, tais dificuldades estão associadas à falta de equipamentos, medicamentos, profissionais e recursos financeiros destinados a viabilizar as equipes para o atendimento a esse público.

Não tem como manter o médico um mês na comunidade porque a gente depende tudo da cidade. Não tem mercado nessas comunidades, lá os moradores vivem da caça e do peixe e, assim, quanto mais chega o verão e o rio fica raso, mais difícil fica o acesso. As nossas equipes ainda levam uma cozinha dentro do barco [...] é do fogão à faca, panela, prato, botija para sair para as comunidades, e são pessoas que moram distante, na mata, perto de varadouros e rios que ficam sem acesso no verão. (GF1).

Alguns municípios não possuem estradas de ligação e, dependendo de onde estão localizados, utilizam como principal meio de transporte o fluvial. Essa dificuldade estende-se para além do transporte às comunidades isoladas, envolvendo, inclusive, a participação dos secretários nas atividades regionais. Em um dos depoimentos, é destacada a dificuldade em se alcançar a meta de vacinação:

Um exemplo de algo que raramente é alcançado é a rotina de vacina. Por que a gente não alcança? Porque é complicado estar buscando a população da zona rural. Fazer rotina de vacina é muito complicado. A gente, às vezes, não consegue campanha em todos os municípios. Raramente os municípios alcançam. (GF2).

Outro gestor destaca a dificuldade no atendimento às mulheres gestantes que residem em comunidades consideradas isoladas, situação compartilhada por vários secretários municipais de saúde presentes nos grupos focais:

[...] eu não consigo fazer o atendimento, por exemplo, de pré-natal para as mulheres de nosso município, tendo em vista que eu levo dois dias e uma estrutura enorme para chegar na última comunidade, que é fronteira com o Peru, e as muIheres dessas comunidades, elas não têm condições. Eu, no máximo, vou para essas comunidades com equipe completa [...] três vezes no ano. E aí, essas mulheres não vão conseguir chegar à unidade básica de saúde de dois em dois meses, por exemplo. (GF1).

Nesse aspecto, também foi citado o elevado número de portarias, decretos e sistemas que devem ser cumpridos sem, entretanto, considerarem as particularidades da grande maioria dos municípios do estado, os quais se defrontam com enormes dificuldades para atingir as metas estipuladas pelo MS.

Gestores dos municípios localizados nas áreas mais isoladas do estado do Acre foram os mais incisivos em relação a essas dificuldades, tendo destacado tanto o transporte terrestre (estradas de difícil tráfego) quanto o fluvial, no caso de acesso às comunidades isoladas, onde para se chegar são necessários dias de viagem e gastos adicionais em infraestrutura.

Dessa forma, observa-se, nas falas, uma crítica em relação ao modo como o MS se posiciona em relação às diferentes regiões do País. Os secretários argumentam que a situação geográfica dos municípios da Região Norte justifica um tratamento diferenciado. Em um dos depoimentos, é relatada a realidade enfrentada pelos municípios para que os agentes comunitários de saúde realizem o seu trabalho:

Aqui, um agente comunitário de saúde leva dois dias, três dias a pé, e andando na lama, para poder chegar no final do percurso dele. No Nordeste, o cara faz de bicicleta e aqui, numa época, acho que em 2000, 2001, 2002 nós tivemos que comprar até cavalos para os agentes comunitários de saúde fazerem o seu serviço. Aí, como é que você vai protocolar, como é que você vai patrimoniar um cavalo? Então, é uma realidade totalmente diferente aqui na Região Norte. (GF2).

$\mathrm{O}$ atendimento às populações da Bolívia e do Peru pelos municípios de fronteira também foi evidenciado nas falas dos gestores. Isto 
tem acarretado um aumento na quantidade de pessoas atendidas, superlotando as unidades de saúde sem o necessário acréscimo no volume de recursos repassados pelo MS, visto que estes são recebidos tendo como referência os dados do Instituto Brasileiro de Geografia e Estatística (IBGE).

Nós temos, hoje, no censo do IBGE, 8.400 e poucas [pessoas]. Nós tratamos mais de 14 mil. Então, nós recebemos o mesmo percentual para acolher um público totalmente diferente. (GF2).

Essa fala é reforçada pelos seguintes argumentos:

A Bolívia também entra no nosso sistema público de saúde. Então, o povo da Bolívia, a gente atende nas nossas unidades básicas de saúde, e que não está na estatística do Ministério. (GF2).

Vem o cidadão da Bolívia, pode vir cidadão do Peru, o haitiano que passa, todo mundo é atendido aqui, e ele quer remédio, e ele quer medicamento, e ele quer ser atendido. Então, essa parte do financiamento totalmente precário... tudo defasado e tudo mínimo. (GF3).

Os depoimentos relevam, ainda, a preocupação com doenças sazonais, pelos municípios de fronteira, intensificada pela constante circulação de pessoas entre municípios e entre países.

Tem que ter cuidado com esse viajante que vem, entra no mercado. A gente tem que estar sempre alerta, sempre preocupado com isso aí. Vem o caso, agora, da dengue, chikungunya e zika. (GF3).

Há grande diversidade socioeconômica e cultural nos estados brasileiros, a exemplo da presença de reservas indígenas, população ribeirinha e população migrante. Acrescentamse a isso a desigualdade no processo de ocupação, a partir da presença de áreas mais antigas e outras muito recentes, bem como a extensa faixa de ocupação de fronteira internacional ${ }^{18}$.
No estado do Acre, gestores reforçaram que, aliada às particularidades regionais, há a escassez de recursos recebidos, que tende a agravar ainda mais os problemas de saúde. Isto porque na Região Norte há, segundo eles, uma captação de recursos baixa e gastos elevados. Um exemplo citado é o controle de doenças tropicais, como ressaltado na fala de um dos secretários:

Hoje, nós estamos tendo 500 casos de malária/ mês. Então, tem que conhecer as diferenças de cada município. É injusto um município que tem 50 casos de malária receba o mesmo financiamento que o município que tem 500 casos de malária/mês. Acho que não é só financiar, tem que conhecer o município, conhecer a região, saber para onde é que eles estão mandando dinheiro e como vai ser trabalhado esse recurso. (GF1).

Ao analisarem os repasses de recursos entre os entes federativos para o financiamento da saúde, Santos e Mendes ${ }^{19}$ sugerem algumas diretrizes para a elaboração de uma proposta de rateio de recursos do governo federal enviado aos estados e municípios, tendo como base os critérios estabelecidos no art. $17 \mathrm{da}$ Lei Complementar $n^{0} 141 / 2012$. Esta proposta dispõe que o rateio dos recursos da União vinculados a ações e serviços públicos de saúde deve observar as necessidades de saúde da população, as dimensões epidemiológica, demográfica, socioeconômica, espacial e de capacidade de oferta de ações e de serviços de saúde. Assim, deve ser incorporada a noção de distribuição equitativa de recursos, baseada em critérios que considerem as diferentes necessidades de saúde da população.

A fragilidade do modelo de transferências do financiamento federal da atenção básica no SUS e sua visão limitada são históricas. Apesar da Portaria MS no 3.992/2017 avançar no sentido de utilizar os recursos financeiros de forma agregada ao orientar os repasses federais em duas modalidades - custeio e investimento -, persiste a vinculação orçamentária do gasto em programas específicos, ou seja, não houve modificações em relação aos critérios de rateio 
dos recursos sustentado nas necessidades em saúde local, contribuindo para as diferenças de atenção à saúde 20 .

Apesar de alguns avanços da Portaria MS $\mathrm{n}^{0} 3.992 / 2017$, em especial, quanto à luta história dos gestores municipais do SUS pelo comando dos recursos de forma geral, a manutenção da lógica dos incentivos financeiros, como a base de cálculo dos valores do Piso da Atenção Básica Variável, estimula a criação de programas que adicionam receita financeira, mantendo o MS como o agente definidor da política de saúde no território nacional. Como consequência, mantém-se, na atenção primária, uma lógica fragmentada ${ }^{20}$.

Uma nova forma de repasse de recursos, com respeito às necessidades de saúde, é ressaltada de forma incisiva nas falas dos secretários municipais, especialmente no que compete ao rateio dos recursos da União, observando a dimensão espacial, presente no art. 17 da Lei ${ }^{\circ}$ 141/2012. Evidencia-se a necessidade de o montante de recursos repassados aos municípios considerar aspectos qualitativos, dadas as características geográficas particulares dos municípios da Região Norte. Há de se ressaltar, entretanto, que o disposto no art. 17 carece de uma metodologia que defina de forma conclusiva os critérios a serem considerados, apesar da existência, desde 2013, de um Grupo de Trabalho que estuda o tema ${ }^{19}$.

Observam-se, portanto, profundas desigualdades regionais na distribuição e no acesso às ações e aos serviços de saúde que ainda permanecem em um país continental e territorialmente heterogêneo como o Brasil. Influenciada por questões histórico-estruturais, econômicas, socioculturais e políticas, essa diversidade de situações geográficas existentes no País confere profundos desafios ao processo de operacionalizar a regionalização em saúde ${ }^{17,21}$.

\section{Percepções sobre o modelo de aten- ção básica}

Apesar da argumentação dos gestores quanto à essencialidade da promoção e da prevenção em saúde, evidencia-se, pelas falas, uma atenção básica perdendo a sua característica e tornando-se mais próxima de um modelo ambulatorial.

Nós temos qualidade de vida? Como é que nós trabalhamos a questão de prevenção? Como é que está a nossa educação em saúde? [...] hoje a atenção básica é vista como ambulatorial. (GF2).

Nesse processo, um elemento importante evidenciado é a fragmentação de programas, ações e serviços de saúde. Conforme esclarecem Santos e Campos"1, há uma fragmentação na saúde pública quando se observa a ampliação de inúmeros programas, cada um direcionado a um tipo de risco ou enfermidade. Este cenário é explicitado em alguns depoimentos.

Descaracterizou totalmente a saúde da família no Brasil. Descaracterizou, ela passou a ser um ambulatório. Porque onde tem todos os profissionais, é um ambulatório: fila da vacina, fila do curativo, da pré-consulta, do teste rápido. (GF3).

[...] hoje, em uma unidade da saúde da família, tem que ter três enfermeiros, não sei quantos técnicos, porque um é só pra vacina, o outro é pra curativo, o outro é só pra isso, quando a estratégia da saúde da família não preconiza isso. (GF3).

Conforme alerta Martins ${ }^{22}$, cresce o temor de que a vida das pessoas vale pouco diante de uma medicina preocupada com a produção de medicamentos e equipamentos com a finalidade principal de ganho econômico.

O SUS é um lugar onde ocorrem disputas entre diversos modelos de assistência à saúde, com a tendência de se manterem modelos hegemônicos, os quais compreendem um modelo assistencial privatista com foco na assistência médico-hospitalar e nos serviços de apoio diagnóstico e terapêutico, bem como no modelo sanitarista, que enfatiza as ações de vigilância epidemiológica e sanitária, além das campanhas de combate às doenças. Entretanto, há esforços em paralelo no sentido 
de se construírem "modelos alternativos que contemplem a articulação das ações de promoção, prevenção e recuperação da saúde, nas dimensões individual e coletiva"23(16).

No processo de implantação da política de saúde, torna-se necessário, ao gestor, a capacidade de negociação política, implicando em relações intergovernamentais, que envolvem diferentes atores políticos e interesses muitas vezes distintos. Neste contexto, os secretários ressaltam a excessiva cobrança feita pela gestão estadual às secretarias municipais quanto às metas a serem atingidas, pactuações e responsabilidades.

O estado, ele coloca o monitoramento e a avaliação dele apenas numa planilha que ele faz de quatro em quatro meses e apresenta lá, que é quadrimestral. Apresenta, e a única coisa que diz pr'a gente é: 'Está ruim aqui, está ruim aqui', 'Que monitoramento e avaliação é esse?'. E coloca do lado assim: 'Observação: o município não fez isso; o município se recusa a fazer isso'. (GF3).

Além de pontuarem as cobranças de outras esferas de gestão, os gestores argumentam que os municípios têm assumido funções que extrapolam o legalmente previsto como sendo de sua competência. Há críticas relacionadas ao governo do estado, que, em algumas situações, não cumpre com o seu papel no nível de complexidade, conforme enfatizado na fala a seguir em relação à cobrança, por parte da secretaria estadual de saúde:

[...] acaba que, por serem cobrados pelo Ministério, eles repassam essa cobrança e acabam que, de forma agressiva, nós ficamos coagidos. São portarias e mais portarias com ameaças: que vai cortar recursos; se não fizer, vai ficar sem dinheiro. E, aí, a gente trabalha com um pessoal pouco qualificado, a rotatividade também é um grande problema. Então, assim, há um subsídio, há um apoio institucional ainda inferior com relação ao que se cobra. Se cobra muito, se quer muito. (GF1).

Nesse processo, há falta de autonomia dos municípios, tendo em vista a grande dependência em relação ao governo federal e estadual para poderem levar a efeito políticas e programas de saúde. Na regionalização, há uma multiplicidade de agentes atuando no espaço interestadual. Os incentivos estão dirigidos para as regiões e os processos fortemente relacionados à esfera estadual e aos municípios envolvidos na pactuação. As formas de coordenação e cooperação entre os entes federados são decisivas para a regionalização da saúde no País ${ }^{17,21}$.

Nesse sentido, para Santos e Campos"1, é indiscutível a relevância da regionalização para sistematizar e dar resolutividade às redes de atenção à saúde, com a região de saúde assumindo um papel central na integração das referências entre os serviços dos mais diversos entes federativos. A questão que se coloca, entretanto, é como proporcionar unidade regional equitativa quando há uma soma articulada de individualidades municipais não simétricas. Para responder a esta questão, os referidos autores destacam a necessária constituição de uma instância unificada de gestão e de planejamento regional, com comando único regional e controle colegiado de municípios, estados e União.

Como alertam Mendes e Louvison ${ }^{\mathbf{1 4}}$, nesses tempos de riscos ao SUS, torna-se essencial resgatar o debate sobre a regionalização, no sentido de contribuir com o fortalecimento de coletivos políticos fortes no enfrentamento aos problemas de saúde. Coadunando com Santos e Campos"11, a região é um caminho para a integração dos serviços em rede, os quais atualmente encontram-se fracionados. Mesmo com os grandes desafios impostos ao processo de regionalização, entende-se que é por meio da região que será possível unir os municípios de forma sistêmica com o intuito de garantir a integralidade da assistência à saúde.

\section{Considerações finais}

Os depoimentos dos secretários municipais de saúde permitem apontar importantes desafios 
de ordem política e operacional no processo de regionalização da saúde no estado do Acre.

Considerada como um espaço cartorial, a CIR não vem cumprindo sua missão. Os secretários a reconhecem como uma instância fortalecedora da política de regionalização em saúde, porém, pela forma como foi concebida e vem sendo implantada, tem sido esvaziada politicamente, apresentando pouca participação e não demonstrando articulações solidárias, já que as verdadeiras e profícuas negociações são realizadas com o executivo diretamente. Assim, ela funciona mais como uma instância formalmente criada e necessária para pactuar decisões já tomadas. As pactuações são articuladas pelos secretários municipais de saúde no âmbito estadual sem discussão colegiada no âmbito da CIR.

Além disso, o Coap sofre resistências para ser implementado. $O$ processo de constituição vertical e a excessiva cobrança por metas e resultados quantitativos de outras instâncias de gestão, sem considerar a realidade dos municípios, têm sido apontados como elementos que dificultam ou mesmo impedem a pactuação. Há municípios com arrecadação própria baixa e altos gastos em logística para as equipes de saúde acessarem as comunidades isoladas. Por outro lado, há aqueles situados em regiões de fronteira e que vem recebendo populações de países vizinhos sem acréscimo de recursos, já que estão vinculados ao critério demográfico (IBGE), considerando apenas a população autóctone.

As barreiras geográficas de acesso da população aos serviços não são consideradas no processo de elaboração das políticas de saúde. Apesar do esforço na elaboração de políticas públicas direcionadas à redução de desigualdades técnicas e financeiras nos municípios, elas não são suficientes para atender as peculiaridades de um país de extensão continental, como é o caso do Brasil.

Já o modelo de atenção básica é associado ao ambulatorial e marcado pela fragmentação de programas, ações e serviços de saúde. Neste contexto, mesmo havendo o aumento da importância das transferências federais, há pouca possibilidade de os municípios exercerem autonomia na determinação da política de saúde. Sobre este aspecto, em dois dos grupos focais realizados, a maioria dos gestores afirmou não gerenciar o FMS. Segundo eles, a secretaria de finanças geralmente concentra tal atribuição. Um dos aspectos negativos desta decisão é a falta de controle, por parte dos secretários municipais de saúde, das informações sobre o orçamento público de saúde, resultando, quando não há articulação adequada no âmbito das secretarias municipais, no comprometimento da gestão sobre os investimentos e gastos prioritários da área.

Diante disso, é relevante questionar em que medida a necessidade de recursos induz à adesão aos programas, por parte dos municípios, independentemente da importância da ação para o atendimento às necessidades de saúde da população local.

É no SUS que a população brasileira geralmente encontra a oferta de serviços de saúde minimamente pensada em termos epidemiológicos e planejada segundo alguns dados locais. Por isto, o presente estudo reafirma os problemas já encontrados na conformação das regiões de saúde no Brasil, de uma maneira geral. Desta forma, é preciso criar mecanismos para o empoderamento das decisões tomadas nos espaços regionais que levem em consideração: a) a garantia do financiamento e da gestão de recursos pactuados no âmbito da região; b) o diálogo com gestores municipais sobre os desafios na implantação do Coap e sua resolutividade; c) a criação de novos arranjos, considerando as barreiras geográficas de acesso às populações de municípios e que levem em consideração as desigualdades em termos espaciais; d) a revisão do critério demográfico para a transferência de recursos em municípios situados em regiões de fronteira; e) a superação da fragmentação de programas, ações e serviços de saúde na atenção básica, a partir de diálogo e pactuação com os municípios; e f) a consolidação de um processo 
de gestão, por meio da elaboração de planos regionais em saúde formulados e pactuados no âmbito da CIR, e que sejam avaliados de forma democrática e participativa.

No entanto, este estudo avança na consolidação do conhecimento sobre as regiões de saúde ao levar luz às especificidades do caso acreano. Assim, pode-se dizer que, somados aos problemas de conformação em âmbito nacional, estão: a) a necessidade do reconhecimento dos aspectos espaciais locais, com destaque à diversidade socioeconômica e cultural dos municípios localizados em áreas isoladas do estado do Acre; b) a descentralização efetiva dos recursos em saúde, tornando o município um agente definidor da política de saúde local, tendo em vista o reconhecimento de que prioridades dos municípios acreanos podem divergir das pactuadas nacionalmente; c) a revisão dos critérios de rateio dos recursos, considerando as necessidades locais, incluindo $\mathrm{o}$ acesso à população ribeirinha e às reservas indígenas; a população imigrante, que entra no sistema de saúde local; e as dificuldades no âmbito da atenção básica; d) o empoderamento da região de saúde por meio de sua liberdade financeira, resultando na promoção da condução de processos técnicos e políticos em seu próprio âmbito.

\section{Colaboradores}

Teston LM (0000-0002-9565-6162)* contribuiu para a concepção, o planejamento, a análise e a interpretação dos dados; na elaboração e revisão crítica do conteúdo; e na aprovação da versão final do manuscrito. Mendes A (0000-0002-5632-4333)* contribuiu para a concepção, o planejamento, a análise e a interpretação dos dados; na elaboração e revisão crítica do conteúdo; e na aprovação da versão final do manuscrito. Carnut L (0000-00016415-6977)* contribuiu para a concepção, o planejamento, a análise e a interpretação dos dados; na elaboração e revisão crítica do conteúdo; e na aprovação da versão final do manuscrito. Louvison MCP (0000-0003-1630-3463)* contribuiu para a concepção, o planejamento, a análise e a interpretação dos dados. 


\section{Referências}

1. Brasil. Decreto $n^{0} 7.508$, de 28 de junho de 2011. Regulamenta a Lei $\mathrm{n}^{\circ} 8.080 / 90$, para dispor sobre a organização do SUS, o planejamento da saúde, a assistência à saúde e a articulação interfederativa, e dá outras providências. Diário Oficial da União. 29 Jun 2011.

2. Viana ALA, Lima LD. O processo de regionalização na saúde: contextos, condicionantes e papel das Comissões Intergestores Bipartites. In: Viana ALA, Lima LD, organizadores. Regionalização e relações federativas na política de saúde do Brasil. Rio de Janeiro: Contra Capa; 2011. p. 11-24.

3. Noronha JC, Lima LD, Machado CV. O Sistema Único de Saúde - SUS. In: Giovanella L, Escorel S, Lobato LVC, et al. Políticas e sistema de saúde no Brasil. 2. ed. rev. e ampl. Rio de Janeiro: Fiocruz; 2012. p. 365-93.

4. Acre. Secretaria de Estado de Saúde, Comissão Intergestores Bipartite (CIB). Resolução CIB nº 36/2012. Rio Branco, AC; 2012.

5. Acre. Secretaria de Estado de Saúde. Plano Estadual de Saúde (2016-2019). Rio Branco, AC; 2016.

6. Acre. Secretaria de Estado de Saúde. Plano Diretor de Regionalização. Rio Branco, AC; 2003.

7. Acre. Secretaria de Estado de Saúde. Plano Estadual de Saúde (2012-2015). Rio Branco, AC; 2012.

8. Westphal MF, Bógus CM, Nogueira-Martins MCF. Métodos qualitativos em nutrição e saúde pública. In: Taddei JAAC, Lang RMF, Longo-Silva G, et al. Nutrição em saúde pública. Rio de Janeiro: Rubio; 2011. p. 25-40.

9. Trad LAB. Grupos focais: conceitos, procedimentos e reflexões baseadas em experiências com o uso da técnica em pesquisas de saúde. Physis. 2009; 19(3):777-96.

10. Bardin L. Análise de conteúdo. São Paulo: Edições $70 ; 2011$.
11. Santos L, Campos GWS. SUS Brasil: a região de saúde como caminho. Saúde Soc. 2015; 24(2):438-46.

12. Carnut L, Narvai PC. Avaliação de desempenho de sistemas de saúde e gerencialismo na gestão pública brasileira. Saúde Soc. 2016; 25(2):290-305.

13. Leite VR, Lima KC, Vasconcelos CM. Financiamento, gasto público e gestão dos recursos em saúde: o cenário de um estado brasileiro. Ciênc. Saúde Colet. 2012; 17(7):1849-56.

14. Mendes A, Louvison M. O debate da regionalização em tempos de turbulência no SUS. Saúde Soc. 2015; 24(2):393-402.

15. Tamaki EM, Tanaka OY, Felisberto E, et al. Metodologia de construção de um painel de indicadores para o monitoramento e a avaliação da gestão do SUS. Ciênc. Saúde Colet. 2012; 17(4):839-49.

16. Rodrigues V, Santos CRI, Pereira, MU. A experiência de planejar e operacionalizar o PMAQ-AB no estado do Acre. Saúde debate. 2014; 38(esp):173-81.

17. Lima LD, Queiroz LFN, Machado CV, et al. Descentralização e regionalização: dinâmica e condicionantes da implantação do Pacto pela Saúde no Brasil. Ciênc. Saúde Colet. 2012; 17(7):1903-14.

18. Albuquerque MV, Mello GA, Iozzi FL. O processo de regionalização em saúde nos estados brasileiros. In: Viana ALA, Lima LD, organizadores. Regionalização e relações federativas na política de saúde do Brasil. Rio de Janeiro: Contra Capa; 2011. p. 117-72.

19. Santos L, Mendes AN. Notas Técnico-Jurídicas Sobre Critérios e Metodologia de Rateio dos Recursos Federais para os Estados e Municípios no SUS. BDM. 2014; 9:647-64.

20. Mendes A, Carnut L, Guerra LDS. Reflexões acerca do financiamento federal da Atenção Básica no Sistema Único de Saúde. Saúde debate. 2018; 42 (esp1): 224-43. 
21. Lima LD, Viana ALA. Descentralização, regionalização e instâncias intergovernamentais no Sistema Único de Saúde. In: Viana ALA, Lima LD, organizadores. Regionalização e relações federativas na política de saúde do Brasil. Rio de Janeiro: Contra Capa; 2011. p. 39-63.

22. Martins PH. Contra a desumanização da medicina: crítica sociológica das práticas médicas modernas. Rio de Janeiro: Vozes; 2003.
23. Gomes WS, Bezerra AFB. Programa de melhoria do acesso e qualidade da atenção básica: reflexões sobre o papel da avaliação na efetivação da integralidade em saúde. Saarbrucken, Deutschland: Novas Edições Acadêmicas; 2014.

Recebido em 25/09/2018

Aprovado em 02/04/2019

Conflito de interesses: inexistente

Suporte financeiro: Não houve 